\title{
ĐẶC ĐIỂM SINH HỌC SINH SẢN CỦA NGAO BẾN TRE (MERETRIX LYRATA) TẠI VÙNG TRIỀU VEN BIỂN TỈNH NAM ĐỊNH
}

\author{
Nguyễn Xuân Thành*, Đỗ Công Thung \\ Viện Tài nguyên và Môi trường biển-Viện Hàn lâm Khoa học và Công nghệ Việt Nam \\ *Email: thanhnx@imer.ac.vn
}

Ngày nhận bài: 3-3-2014

\begin{abstract}
TÓM TÄT: Kết quả thu thập và phân tích 820 mẫu ngao Bến Tre (Meretrix lyrata, Sowerby 1851) ở các vây nuôi tại vùng triều ven biển tỉnh Nam Định tù tháng 2/2012 đến tháng $1 / 2013$ cho thấy: Mùa vu sinh sản của ngao Bến Tre hàng năm được xác định tù̀ giữa tháng 4 đến đầu tháng 9 , tập trung tù giữa tháng 5 đến cuối tháng 7. Ở các tháng trong năm tỷ lệ con đực luôn chiếm uu thế so với con cái trong quần thể ngao. Trong mùa sinh sản tỷ lệ ngao đục và ngao cái tiến dần tới sự cân bằng hơn, giao động tù̀ 0,86 đến 1,14. Ngao Bến Tre thành thuc sinh dục lần đầu khi chiều dài đạt trên $31 \mathrm{~mm}$, khối luợng trên $15 \mathrm{gram}$. Sức sinh sản tuyệt đối giao động tù 1.530 .000 đến 4.470.000 trúng/cá thể.
\end{abstract}

Tù khóa: Ngao Bến Tre, Nam Định, sinh học sinh sản, mùa vu sinh sản.

\section{MỞ ĐÀ̀}

Ngao Bến Tre (Meretrix lyrata) là loại động vật thân mềm hai mảnh vỏ có giá trị kinh tế cao, phân bố tự nhiên, được khoanh nuôi và cho sản lượng lớn tại các tỉnh Đồng bằng Sông Cửu Long [4]. Vào những năm 2004 - 2006, ngao Bến Tre được di giống ra nuôi tại các tỉnh ven biển miền Bắc như Nam Định, Thái Bình, Hải Phòng, Ninh Bình, Thanh Hóa [8]. Do thích nghi nhanh chóng với môi trường ở khu vực này nên chúng đã sinh trưởng phát triển và tham gia sinh sản. Kết quả là việc nuôi ngao Bến Tre tại đây liên tục phát triển cả về diện tích cũng như năng suất nuôi. Đến nay tại vùng ven biển tỉnh Nam Định, ngao Bến Tre đã phát triển lấn át các loài ngao bản địa, sản lượng của chúng chiếm khoảng 85 - 90\% cơ cấu sản lượng động vật thân mềm của tỉnh [6]. Nghiên cứu đầy đủ về đặc điểm sinh học sinh sản của Ngao Bến Tre tại Việt Nam đến nay mới chỉ có công trình của Trương Quốc Phú [3] được thực hiện tại ven biển Tiền Giang, nơi có loài này phân bố tự nhiên với điều kiện nhiệt độ nước cao và tương đối ổn định (khoảng $26-32^{\circ} \mathrm{C}$ ).
Ngao Bến Tre sau khi được di giống ra các tỉnh ven biển miền Bắc, nơi có điều kiện nhiệt độ môi trường biến động lớn, với nhiệt độ cao vào mùa hè (có thời điểm lên đến trên $35^{\circ} \mathrm{C}$ ) và thấp vào mùa đông (có lúc chỉ dưới $15^{\circ} \mathrm{C}$ ) nhưng chúng đã thích nghi và phát triển tốt, tạo quần đàn bố mẹ thành thục sinh dục ngay trong vây nuôi và tham gia sinh sản. Tuy vậy, cho đến nay vẫn chưa có công bố chính thức nào đề cập đến vấn đề này. Để góp phần cung cấp các luận cứ khoa học cho việc việc lập kế hoạch sản xuất, bảo vệ đa dạng sinh học, phát triển bền vững nghề nuôi ngao tại địa phương, trong các năm 2012, 2013 chúng tôi đã tiển hành nghiên cứu đặc điểm sinh học của loài ngao Bến Tre nhằm cung cấp các thông tin cơ bản về một số đặc điểm sinh học sinh sản của ngao Bến Tre ở vùng nghiên cứu.

\section{PHƯƠNG PHÁP NGHIÊN CÚU}

\section{Vật liệu nghiên cứu}

Tổng số 820 mẫu ngao đã được thu thập tại các vây nuôi ở ven biển Nam Định trong khoảng thời gian từ tháng $2 / 2012$ đến tháng $1 / 2013$. Tần 
suất thu mẫu 2 lần/tháng, mỗi lần thu 30 - 35 cá thể trên quần đàn ngao, với kích thước chiều dài của ngao từ $20 \mathrm{~mm}$ đến $50 \mathrm{~mm}$.

\section{Phương pháp nghiên cứu}

Đo chiều dài của ngao bằng thước kẹp (palmer) điện tử có độ chính xác 0,1 mm.

Cân khối lượng cá thể (cả vỏ), phần thân mềm của ngao bằng cân kỹ thuật (Adam/AQT 200 của Anh, độ chính xác $0,1 \mathrm{~g}$ ).

Sản phẩm sinh dục của ngao được thu và bảo quản theo phương pháp của Quayle và Newkirk [5], cách tiến hành cụ thể như sau: Gạt nhe mang và màng áo ra hai bên để quan sát tuyến sinh dục, tiếp đó từ chỗ bi cắt ở phần lưng, dùng dao gạt nhẹ để thu sản phẩm sinh dục. Đối với cá thể chưa thành thục, tuyến sinh dục không căng đầy, rạch ngang phần nội tạng ờ vị trí quan sát thấy tuyến sinh dục. Đối với cá thể thành thục có thể dễ dàng tách được sản phẩm sinh dục từ phía lưng. Bảo quản các sản phẩm sinh dục đã thu bằng dung dịch formol (nồng độ 10\%).

Quan sát sự phát triển của tuyến sinh dục, tế bào sinh dục của ngao theo thang 5 bậc đã được mô tả bởi Helm và Bourne [1]. Cố định tuyến sinh dục bằng dung dịch formol nồng độ $10 \%$. Tiến hành loại bỏ nước bằng dung dịch etanol (nồng độ $70 \%$ ), tiếp theo làm sạch nước bằng xylene hoặc cồn. Sau đó đúc parafin và cắt lát mỏng từ $5-7 \mu \mathrm{m}$ bằng máy cắt Microtome. Nhuộm mẫu bằng dung dịch hematoxylin và eosin. Quan sát tiêu bản bằng kính hiển vi quang học ở độ phóng đại khoảng 100 - 400 lần.

Xác định mùa vụ sinh sản: Tiến hành quan sát tuyến sinh dục của ngao trong các đợt thu mẫu để xác định sự hiện diện cũng như số lượng cá thế đã thành thục sinh dục (giai đoạn III, IV).

Cơ cấu giới tính: Xác định cơ cấu giới tính theo thời gian và theo nhóm kích thước dựa trên sự quan sát số lượng cá thể đực, cá thể cái và các cá thể không phân biệt từ mẫu ngẫu nhiên tại các lần thu mầu.

Kích thước thành thục sinh dục lần đầu: Được xác định cho nhóm cá thể có kích thước nhỏ nhất mà trong đó trên $50 \%$ số cá thể có tuyến sinh dục ở giai đoạn III, IV.
Xác định sức sinh sản.

Sức sinh sản tuyệt đối (SSSTĐ - Fa) là toàn bộ số lượng trứng ở giai đoạn III, IV của một cá thể ngao. $\mathrm{Fa}$ được tính cho từng nhóm kích thước vào đầu mùa sinh sản.

Cách xác định $\mathrm{Fa}$ như sau: Tách buồng trứng ra khỏi phần thân mềm và hòa tất cả số trứng vào một thể tích nước biển lọc sạch nhất định. Dung dịch chứa trứng được hút bỏ các tạp chất, khuây đều rồi lấy mẫu $1 \mathrm{ml}$. Đếm trứng bằng buồng đếm động vật phù du. Tính số lượng trứng của một cá thể theo công thức:

$$
\mathrm{Fa}=\mathrm{n} \times \mathrm{V}
$$

Trong đó: Fa là sức sinh sản tuyệt đối; n: số trứng trong $1 \mathrm{ml}$; $\mathrm{V}$ : thể tích nước biển lọc sạch chứa trứng $(\mathrm{ml})$.

Sức sinh sản tương đối (Frg): là tỉ số giữa sức sinh sản tuyệt đối với khối lượng toàn thân hoặc khối lượng thân mềm. Các công thức tính sức sinh sản tương đối là:

$$
\operatorname{Frg}_{1}=\mathrm{Fa} / \mathrm{Wtt} ; \quad \operatorname{Frg}_{2}=\mathrm{Fa} / \mathrm{Wtm}
$$

Trong đó: $\operatorname{Frg}_{1}$ : Sức sinh sản tương đối tính theo khối lượng toàn thân;

$\mathrm{Frg}_{2}$ : Sức sinh sản tương đối tính theo khối lượng thân mềm;

Wtt: Khối lượng toàn thân cả vỏ;

Wtm: Khối lượng phần thân mềm.

Các thao tác cân trọng lượng, đo kích thước, mổ ngao, xác định tî̉ lệ đực cái, xác định sự phát triển của tuyến sinh dục, sức sinh sản tương đối, tuyệt đối được tiến hành tại Việ̂n Tài nguyên và Mồi trường biển. Đúc mầu, cắt tiêu bản được thực hiện tại Phòng mô bệnh phẩm, Bệnh viện Việt Tiệp Hải Phòng.

\section{Xử lí số liệu}

Các số liệu được thể hiện bằng trung bình (Mean) \pm Sai số chuẩn (Standard error) sử dụng công cụ thống kê Descriptive Statistics và Anova Single factor để phân tích số liệu trên MS Excel.

\section{KẾT QUẢ VÀ THẢO LUẬN}

Cơ cấu giới tính của ngao Bến Tre ở vùng ven biển Nam Định 
Nhìn hình dạng bên ngoài rất khó xác định được giới tính của ngao. Để phân biệt được giới tính đực, cái cần thiết phải tiến hành giải phẫu và quan sát tuyến sinh dục (TSD) của chúng.

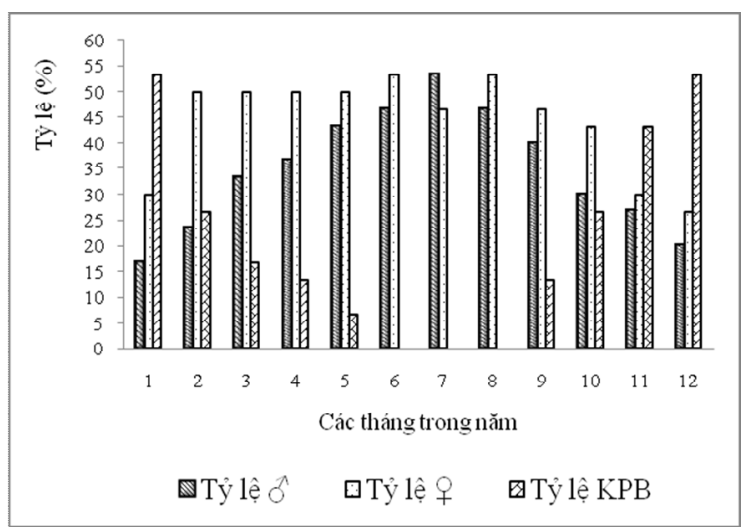

Ghi chú: ô- ngao đưc; + - ngao cái ; KPB ngao có tuyến sinh dục không phân biệt đực, cái

Hình 1. Cơ cấu giới tính của ngao Bến Tre qua các tháng trong năm

Kết quả quan sát giới tính ngao Bến Tre từ tháng $2 / 2012$ đến tháng $1 / 2013$ ở vùng nghiên cứu cho thấy, không phát hiện có ngao lưỡng tính trong các mẫu đã thu được. Kểt quả này khác với công bố Trương Quốc Phú [3] khi nghiên cứu về loài này tại ven biển Tiền Giang và tác giả đã phát hiện tỷ lệ ngao lưỡng tính tại đây chiếm từ $3,7 \%$ đến $20,5 \%$, tăng dần trong mùa sinh sản. Ngoài mùa sinh sản (từ tháng 9 đến tháng 1) không phát hiện thấy cá thể ngao lưỡng tính [3].
Kết quả nghiên cứu về sự biến động giới tính của ngao Bến Tre tại Nam Định theo thời gian trong năm được thể hiện ở hình 1 .

Qua đó thấy rằng, trong quần thể ngao tỷ lệ con đực luôn thấp hơn con cái ở hầu hết các tháng trong năm với tỷ lệ đực/cái dao động từ 0,47 đến 0,88 (trừ tháng 7 tỷ lệ đực/cái $=1,14$ ). Tỷ lệ ngao không phân biệt giới tính (KPB) tăng cao vào các tháng ngoài mùa sinh sản, cao nhất bắt gặp vào tháng 12 và tháng $1(53,3 \%)$, sau đó giảm dần từ tháng 2 đến tháng 5 . Đến mùa sinh sản, do TSD ngao lúc này hầu hết ở giai đoạn thành thục nên giới tính ngao có thể dễ dàng nhân biết được, tỷ lệ đực/cái tiến dần đến sự cân bằng hơn, dao động khoảng 0,86 0,88 . Kết quả này cũng tương tự đối với ngao dầu [7]. Tuy nhiên ở Tiền Giang tỷ lệ đực/cái xuống rất thấp lại bắt gặp ngoài mùa sinh sản [3]. Đây là điểm khác biệt đáng chú ý về cơ cấu giới tính của cùng một loài ngao tại hai khu vực có điều kiện khí hậu khác nhau.

Kết quả nghiên cứu cơ cấu giới tính của ngao theo nhóm kích thước được trình bày trong bảng 1. Ở nhóm ngao có chiều dài vỏ nhỏ (<30 mm), tỷ lệ con đực có xu thế lớn hơn con cái trong khi ở những nhóm cá thể có chiều dài lớn hơn (từ 31 đến $50 \mathrm{~mm}$ ), tỷ lệ con đực/con cái gần như là tương đương. Kết quả này sẽ là cơ sở khoa học cần thiết cho việc lựa chọn ngao bố mẹ trong quá trình sản xuất giống ngao nhân tạo.

Bảng 1. Cơ cấu giới tính của ngao Bến Tre theo các nhóm kích thước

\begin{tabular}{|c|c|c|c|c|c|c|c|}
\hline $\begin{array}{l}\text { Nhóm kích } \\
\text { thước (mm) }\end{array}$ & $\begin{array}{l}\text { Số mẫu } \\
\text { quan sát }\end{array}$ & Số cá thể & Số cá thể & $\begin{array}{c}\text { Số cá thể } \\
\text { KPB }\end{array}$ & $\begin{array}{c}\text { Tỷ lệ } \hat{\jmath} \\
(\%)\end{array}$ & $\begin{array}{c}\text { Tỷ lệ }+ \\
(\%)\end{array}$ & $\begin{array}{c}\text { Tỷ lệ KPB } \\
\text { (\%) }\end{array}$ \\
\hline$<30$ & 70 & 18 & 13 & 39 & 25,71 & 18,57 & 55,71 \\
\hline $41-50$ & 100 & 45 & 48 & 7 & 45,00 & 48,00 & 7,00 \\
\hline
\end{tabular}

Ghi chú: ô- ngao đục; + - ngao cái ; KPB - ngao có tuyến sinh dục không phân biệt đục, cái

Sự phát triển tuyến sinh dục và kích thước thành thục sinh dục lần đầu của ngao ở vùng nghiên cứu

\section{Sự phát triển tuyến sinh dục của ngao}

Khi chưa thành thục sinh dục, TSD của ngao rất khó phân biệt bằng mắt thường. Khi thành thục sinh dục, TSD căng phồng và nổi cao, có hình dạng như múi bưởi kéo dài từ cơ khép vỏ đến chân, TSD con đực có màu trắng nhạt, TSD con cái có màu vàng nhạt. Để phân biệt giới tính ngao một cách chính xác cần phải quan sát tế bào sinh dục hoặc tiêu bản lát cắt TSD trên kính hiển vi điện tử. 
Các giai đoạn phát triển TSD ngao Bến Tre được phân chia dựa theo thang 5 bậc của Quayle và Newkirk [5] và mô tả của Helm and Bourne [1] như sau:

Giai đoạn 0: Tuyến sinh dục chưa phát triển, chưa thể phân biệt giới tính.

Giai đoạn I (Giai đoạn phát dục): Các noãn nguyên bào mới xuất hiện, bắt đầu hình thành các giao tử đực và giao tử cái.

Giai đoạn II (Giai đoạn sinh trưởng): Ở giai đoạn này kích thước tuyến sinh dục đã tăng nhanh do các noãn nguyên bào phát triển.

Giai đoạn III (Giai đoạn thành thục): Hình thái ngoài tuyến sinh dục có dạng căng phồng, kích thước TSD tăng lên tối đa ở cuối giai đoạn này. Sản phẩm sinh dục có thể chảy ra khi ấn nhẹ vào phần thân mềm và có thể hòa tan trong nước.

Giai đoạn IV (Giai đoạn sau đẻ): Ở giai đoạn IV, tuyến sinh dục gần hết các sản phẩm sinh dục, chỉ còn sót lại vài noãn bào giai đoạn chín. Tuyến sinh dục như co lại, mềm nhũn, bị chia cắt bởi các dạng trong suốt dạng rễ cây.

\section{Kích thuoớc thành thuc sinh dục lần đầu của ngao}

Kết quả xác định kích thước thành thục sinh dục lần đầu của ngao Bến Tre tại ven biển Nam Định thể hiện tại hình 2 và bảng 2 .

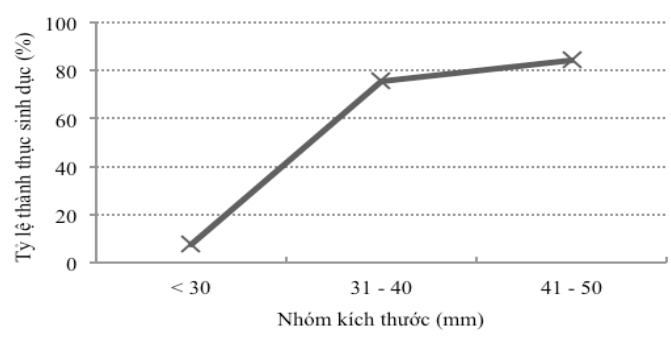

Hình 2. Kích thước thành thục sinh dục lần đầu của ngao Bến Tre

Bảng 2. Sự phát triển tuyến sinh dục ngao theo nhóm kích thước

\begin{tabular}{ccccc}
\hline $\begin{array}{c}\text { Nhóm kích thước } \\
(\mathbf{m m})\end{array}$ & $\begin{array}{c}\text { Khối lượng trung } \\
\text { bình (g/con) }\end{array}$ & $\begin{array}{c}\text { Tổng số mẫu quan } \\
\text { sát (con) }\end{array}$ & $\begin{array}{c}\text { Số cá thể thành thục } \\
\text { sinh dục (con) }\end{array}$ & $\begin{array}{c}\text { Tỷ lệ thành thục } \\
\text { sinh dục (\%) }\end{array}$ \\
\hline$<30$ & 7,28 & 40 & 3 & 7,50 \\
$31-40$ & 14,26 & 90 & 68 & 75,56 \\
$41-50$ & 24,72 & 45 & 38 & 84,44 \\
\hline
\end{tabular}

Kết quả nghiên cứu cho thấy, ngao Bến Tre tại ven biển Nam Định thành thục sinh dục lần đầu ở nhóm kích thước chiều dài trên $31 \mathrm{~cm}$, tương ứng với khối lượng trên 14 gram. Kết quả này cũng tương tự với công bố của Trương Quốc Phú khi nghiên cứu trên ngao Bến Tre tại miền Nam [3]. Tuy nhiên, khi so sánh với ngao dầu $(M$. meretrix) ở cùng khu vực ven biển Nam Định [7] thì ngao Bến Tre thành thục sinh dục lần đầu ở kích thước nhỏ hơn.

\section{Sức sinh sản và mùa vụ sinh sản của ngao Bến Tre ở vùng nghiên cứu}

Súc sinh sản
Kết quả nghiên cứu về sức sinh sản của ngao Bến Tre theo các nhóm kích thước vào mùa sinh sản được thể hiện ở bảng 3 .

Kết quả ở bảng 3 cho thấy, sức sinh sản của ngao Bến Tre tương đối lớn. Sức sinh sản tuyệt đồi $(\mathrm{Fa})$ trung bình của ngao ngao Bến Tre với ở kích chiều dài từ $31-50 \mathrm{~mm}$ đạt 2.938 .750 trứng/cá thể, giao động từ 1.530 .000 - 4.470.000 trứng/cá thể. Sức sinh sản tương đối tính theo khối lượng toàn thân $\left(\operatorname{Frg}_{1}\right)$ đạt trung bình 118.262 trứng/gam, giao động 81.199 - 155.992 trứng/gam. Sức sinh sản tương đối tính theo khối lượng thân mềm $\left(\mathrm{Frg}_{2}\right)$ đạt trung bình 682.013 trứng/gam, giao động từ 457.243 - 898.094 trứng/gam. 
Đặc điểm sinh học sinh sản của ngao Bến Tre ...

Bảng 3. Sức sinh sản của ngao Bến Tre tại vùng triều ven biển tỉnh Nam Định

\begin{tabular}{|c|c|c|c|}
\hline \multirow{3}{*}{ Nhóm kích thước $(\mathrm{mm})$} & \multicolumn{3}{|c|}{ Sức sinh sản } \\
\hline & \multirow{2}{*}{$\begin{array}{c}\begin{array}{c}\text { Súrc sinh sản tuyệt đối } \\
\text { (trứng/cá thể) }\end{array} \\
F a\end{array}$} & \multicolumn{2}{|c|}{ Sức sinh sản tương đối (trứng/g) } \\
\hline & & $\operatorname{Frg} 1$ & $\operatorname{Frg} 2$ \\
\hline $31-40$ & $2232500 \pm 277860^{a}$ & $121383 \pm 14440^{a}$ & $714567 \pm 73401^{a}$ \\
\hline $41-50$ & $3645000 \pm 391077^{b}$ & $115140 \pm 12557^{\mathrm{a}}$ & $649458 \pm 65892^{a}$ \\
\hline $\begin{array}{c}\text { Trung bình } 2 \text { nhóm kích } \\
\text { thước }\end{array}$ & $2938750 \pm 347236$ & $118262 \pm 8936$ & $682013 \pm 47289$ \\
\hline
\end{tabular}

Ghi chú: Số liệu có các chũ cái in thwờng khác nhau trong cùng một cột cho thấy sụ khác biệt có ý nghĩa thống kê $(P<0,05)$. Số liệu có các chũ cái in thường giống nhau trong cùng một cột cho thấy không có sụ khác biệt có ý nghĩa thống kê $(P>0,05)$.

\section{Mùa vu sinh sản}

Các giai đoạn phát triển của tuyến sinh dục ngao Bến Tre tại Nam Định theo thời gian trong năm được biểu diễn ở hình 3.
Kết quả nghiên cứu cho thấy, có sự sai khác về sự phát triển tuyến sinh dục ngao Bến Tre tại Nam Định theo các tháng trong năm và tuân theo quy luật (hình 3).

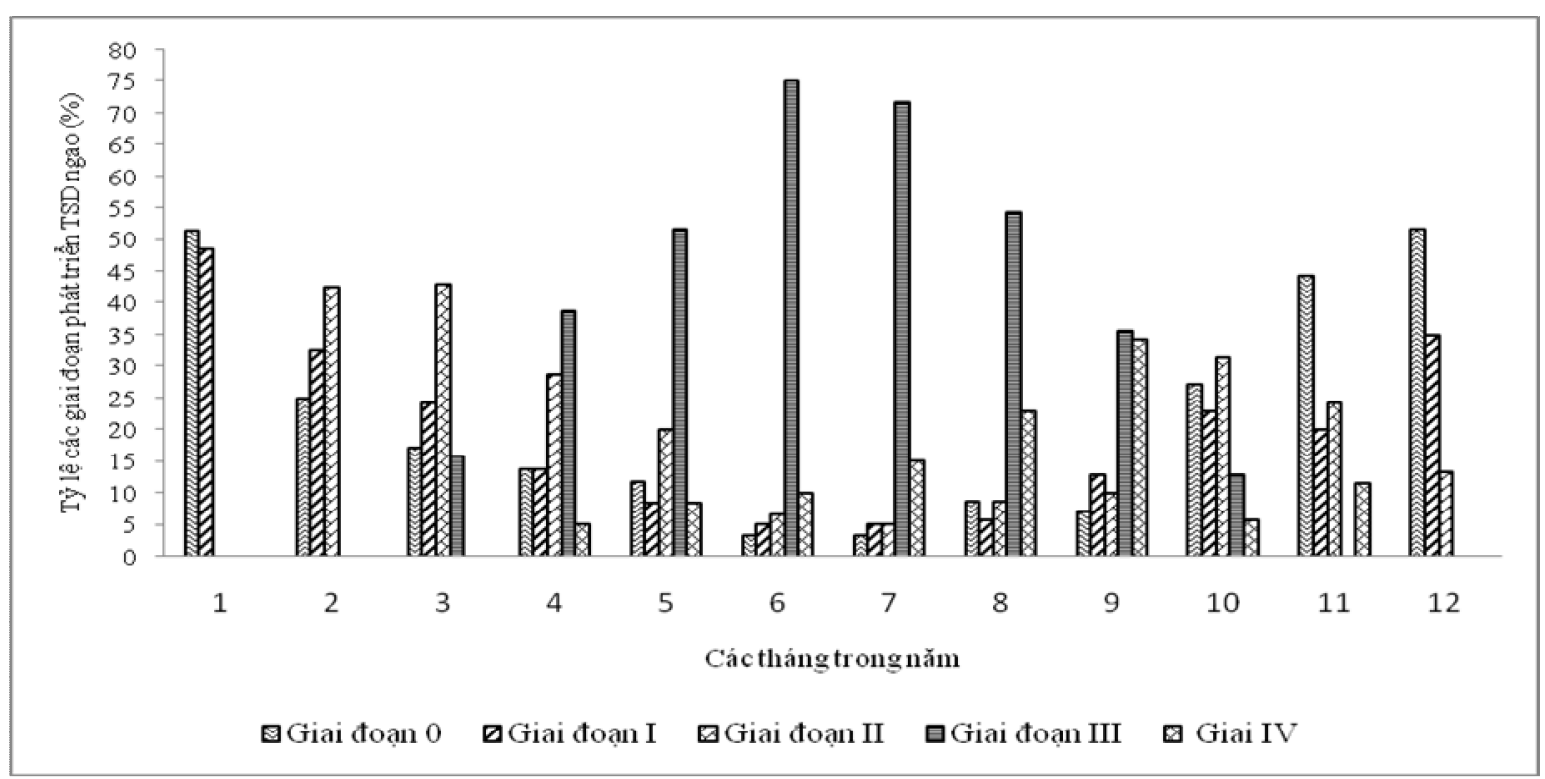

Hình 3. Tỷ lệ các giai đoạn phát triển của TSD ngao Bến Tre tại Nam Định theo thời gian

Tuyến sinh dục ngao ở các giai đoạn còn non (giai đoạn 0 và $\mathrm{I}$ ) phân bô hầu hết các tháng trong năm, trong đó tập trung cao từ tháng 10 năm trước đến tháng 3 năm sau và có xu hướng tăng dần từ tháng 10 đến tháng 1 . Sau đó giảm dần và đến tháng 7 có tỷ lệ thấp $(8,3 \%)$.

Giai đoạn sinh trưởng tuyến sinh dục của ngao (giai đoạn II) phân bố nhiều trong các tháng 2 và 3 , trong khi đó tháng 1 không phát hiện thấy ngao có TSD ở giai đoạn II.
Giai đoạn thành thục của TSD (giai đoạn III) có xu hướng tăng dần từ tháng $3(15,7 \%)$ đến tháng 7 , tập trung cao vào tháng $6(75 \%)$ và tháng $7(71,7 \%)$, sau đó giảm dần, từ tháng 11 năm trước đến tháng 2 năm sau không phát hiện thấy ngao có TSD ở giai đoạn III.

Giai đoạn thoái hóa sau đẻ (giai đoạn IV) của TSD ngao Bến Tre xuất hiện từ tháng 4 , tăng dần đến tháng 9 , sau đó giảm đến tháng 11 . Từ tháng 12 năm trước đến tháng 3 năm sau không phát hiện thấy ngao có TSD ở giai đoạn IV. 
Các kết quả nghiên cứu sự phát triển TSD của ngao Bến Tre cho thấy, ở miền Bắc nước ta không có ngao sinh sản từ tháng 10 đến tháng 2 vì thời gian này TSD của ngao hầu hết ở giai đoạn còn non hoặc đang sinh trưởng, không có ngao thành thục sinh dục, trong khi đó tại tỉnh Tiền Giang (miền Nam) tháng 11 ngao vẫn có thể sinh sản rải rác [3].

Từ cuối tháng 3 , đầu tháng 4 ngao bắt đầu thành thục sinh dục và tham gia sinh sản. Mùa vụ sinh sản được xác định bắt đầu từ giữa tháng 4 đến đầu tháng 9 , mùa sinh sản tập trung từ giữa tháng 5 đển cuối tháng 7 . Ngoài khoảng thời gian này ngao tham gia sinh sản với tỷ lệ thấp, chất lượng sinh sản giảm. Theo Trương Quốc Phú [3] thì mùa sinh sản ngao ở miền Nam (từ tháng 3 đến tháng 11) được chia thành 2 kỳ trong năm, kỳ đầu từ tháng 3 đến tháng 5 , thời kỳ thứ 2 vào lúc kết thúc mùa mưa khoảng tháng 9 đến tháng 11 và được gọi là mùa phụ. Tuy nhiên, Nguyễn Đình Hùng [2] lại cho rằng, mùa sinh sản chính của ngao tại miền Nam từ tháng 5 đến tháng 7 và mùa phụ từ tháng 11 đến tháng 1 năm sau (có năm không thấy xuất hiện mùa phụ). Như vậy, mùa vụ sinh sản của ngao Bến Tre tại ven biển Nam Định xuất hiện chậm hơn và kết thúc sớm hơn so với ngao phân bố ở Tiền Giang (miền Nam) nhưng mùa vụ sinh sản của ngao tại miền Bắc tập trung hơn và không kéo dài như ngao tại miền Nam.

\section{KẾT LUẬN}

Nghiên cứu này cho thấy ngao Bến Tre (Meretrix lyrata) tại vùng triều ven biển tỉnh Nam Định có một số đặc điểm sinh học sinh sản của như sau:

Không phát hiện thấy hiện tượng lưỡng tính trong quần thể ngao, tỷ lệ con cái luôn chiếm ưu thế so với con đực, vào mùa vụ sinh sản tỷ lệ đực/cái tiến gần đến sự cân bằng hơn.

Sự phát triển tuyến sinh dục (TSD) của ngao Bến Tre trải qua 5 giai đoạn với thời gian trong năm như sau: Từ tháng 10 năm trước đến tháng 3 năm sau TSD ngao hầu hết ở giai đoạn còn non (giai đoạn $0, \mathrm{I}$ ). Từ tháng 2 đến tháng 3 là thời gian sinh trưởng của TSD. Từ tháng 4 đến tháng 8 hầu hết ngao ở giai đoạn chín sinh dục. Cuối tháng 8 đến tháng 9 tháng TSD của ngao chủ yếu ở giai đoạn thoái hóa.
Ngao Bến Tre thành thục sinh dục lần đầu khi có kích thước chiều dài đạt trên $31 \mathrm{~mm}$, khối lượng đạt 15 gram.

Sức sinh sản tuyệt đối $(\mathrm{Fa})$ của ngao Bến Tre giao động từ 1.530 .000 -
4.470 .000 trứng/cá thể.

Mùa vụ sinh sản hàng năm của ngao Bến Tre được xác định từ giữa tháng 4 đến cuối tháng 8 . Mùa vụ sinh sản chính từ giữa tháng 5 đến cuối tháng 7 .

Lời cảm ơn: Xin chân thành cảm ơn đề tài KC.09.07/11 - 15 đã hỗ trợ để thực hiện nghiên cứu này.

\section{TÀI LIỆU THAM KHẢO}

1. Helm M. and N. Bourne, 2004. Hatchery culture of bivalves, a practical manual (FAO Consultant). FAO fisheries technical, 2004, $471 \mathrm{p}$.

2. Nguyễn Đình Hùng, 2003. Nghiên cứu sản xuất nghêu giống $(M$. Lyrata). Tuyển tập báo cáo khoa học. Hội thảo ĐVTM toàn quốc lần thứ ba. Nxb. Nông nghiệp, tp. Hồ Chí Minh. Tr. 100-114.

3. Trưong Quốc Phú, 1999. Nghiên cứu một số đặc điềm sinh học, sinh hóa và kỹ thuật nuôi nghêu đạt năng suất cao. Luân án Tiến sĩ khoa học Nông nghiệp. Đại học Thủy sản, 129 tr.

4. Nguyễn Hũu Phụng, Võ Sĩ Tuấn và Nguyễn Huy Yết, 2001. Phân bố và nguồn lợi động vật thân mềm kinh tế thuộc lớp chân bụng (Gastropoda) và lớp hai mảnh vỏ (Bivalvia) ở ven biển Việt Nam. Tuyển tập báo cáo khoa học Hội thảo động vật thân mềm toàn quốc lần thứ nhất. Nxb. Nông nghiệp. Tp. Hồ Chí Minh. Tr. 27-60.

5. Quayle D. B. and G. F. Newkirk, 1989. Farming Bivalve Molluscs Methods for Study and Development Advances in World Aquaculture. Published by the World Aquaculture Society in Association with International Development Research Center. Volume I, $294 \mathrm{p}$.

6. Nguyễn Xuân Thành, Phạm Thược, Trần Công Khôi, 2013. Hiện trạng và định hướng phát triển nuôi ngao tại Nam Định. Tạp chí Khoa học và Công nghệ biển, Tập 13, Số 1. Tr. 88-94. 
7. Nguyễn Xuân Thành, 2013. Đặc điểm sinh học sinh sản của ngao dầu (Meretrix meretrix) tại vùng triều ven biển tỉnh Nam Định. Tạp chí Khoa học và Công nghệ biển, Tập 13, Số 4. Tr. 357-364.
8. Do Cong Thung, Do Dinh Thinh, Le Thi Thuy, 2013. Mollusks Resources in Western Coast of the Tonkin Gulf. Journal of Earth Science and Engineering 1 (2013), pp. 35-41.

\title{
THE REPRODUCTIVE BIOLOGY OF LYRATE ASIATIC HARD CLAM (MERETRIX LYRATA) IN THE INTERTIDAL ZONE OF NAM DINH PROVINCE
}

\author{
Nguyen Xuan Thanh, Do Cong Thung
}

Institute of Marine environment and resources -VAST

\begin{abstract}
Lyrate Asiatic hard clam (Meretrix lyrata, Sowerby 1851) were collected in the farm of coastal Nam Dinh province, from February 2012 to January 2013 for this study. The results showed that the spawning season was from mid April to early September and the peak of spawning occurred from mid May to late July. Monthly, rate of males was dominant in the population. In spawning season rate of a male/female got close to balance, ranged from 0.86 to 1.14. The first size sexual maturity of the hard clam is over $31 \mathrm{~mm}$ in length and over $15 \mathrm{gr}$ in weight. Absolute fecundity (Fa) ranged from 1,530,000 - 4,470,000 eggs/individual.
\end{abstract}

Keywords: Meretrix lyrata, Nam Dinh, reproductive biology, rpawning season. 